\title{
TESTE DO CARVALHO, DE JANUSZ SZUBER, COMO UMA "PARÁBOLA SOBRE A EXISTÊNCIA"
}

\author{
"Teste do Carvalho" (The Test of an Oak) of Janusz Szuber as a "Parable \\ of Existence"
}

\author{
Wojciech MARYJKA \\ Uniwersytet Rzeszowski \\ Universidade de Rzeszów \\ wmaryjka@ur.edu.p1 \\ https://orcid.org/0000-0001-5324-041X
}

\begin{abstract}
RESUMO: No presente artigo, o autor apresenta a problemática das obras de Janusz Szuber, excelente poeta, natural de Sanok, na região da Subcarpácia. Temas selecionados são tratados pelo autor, tendo como base o opúsculo bilíngue, polonês-português, que contém uma seleção de poemas de Szuber intitulado Próba dębu / Teste do carvalho publicado em 2019 e traduzido por Zygmunt Wojski. O autor expõe o perfil criativo de Szuber através de poemas que mostram a sua identidade poética relacionada com o lugar de moradia (Sanok, à beira das montanhas Bieszczady), histórias familiares, fascinação pela pintura (como as de Nikifor Krynicki e Zdzisław Beksiński) e inspirações literárias. Tem-se a visão do poeta que observa o mundo com notável apreciação aos seus detalhes. É a partir do concreto que se iniciam as histórias universais contadas por Szuber sobre a existência no mundo. PALAVRAS-CHAVE: Janusz Szuber; Poesia polonesa; Tradução ao português; Inspirações poéticas.
\end{abstract}

Tradução do resumo: Milena Woitovicz Cardoso

SUMMARY: This article examines the works of Janusz Szuber who is a renowned poet from a town of Sanok in the south-eastern Polish region of Podkarpacie. Based on the bilingual Polish-Portuguese selection of Szuber's poems entitled Próba dębu / Teste do carvalho (English: The Test of an Oak) published in 2019 and translated by Zygmunt Wojski, the author examines a variety of themes. The author presents Szuber's creative profile, reaching to the poems that disclose the spaces of his poetic identity related with his place of residence (such as Sanok and the hills and crags of the Bieszczady Mountains), family stories, and his fascination with paintings (including the paintings of Nikifor Krynicki and Zdzisław Beksiński) as well as literary inspirations. The resulting image is that of a poet who observes the world with a notable appreciation of its details. This very specific locality gives rise to Szuber's universal stories about being in the world. 
KEY WORDS: Janusz Szuber; Polish poetry; Portuguese translation; Poetic inspirations.

STRESZCZENIE: Artykuł Wojciecha Maryjki przedstawia problematykę twórczości Janusza Szubera, wybitnego poety, pochodzącego z Sanoka na Podkarpaciu. Wybrane zagadnienia omawiane są przez autora w oparciu o dwujęzyczny, polskoportugalski, wybór wierszy Szubera zatytułowany Próba dębu / Teste do carvalho, wydany w 2019 roku i przetłumaczony przez Zygmunta Wojskiego. Maryjka prezentuje twórczą sylwetkę Szubera sięgając po wiersze odsłaniające przestrzenie jego poetyckiej tożsamości związane $\mathrm{z}$ miejscem zamieszkania (Sanok, zakątki Bieszczadów), rodzinnymi historiami, fascynacją malarstwem (m.in. Nikifora Krynickiego i Zdzisława Beksińskiego), literackimi inspiracjami. Otrzymujemy obraz poety prowadzącego obserwację, którą wyróżnia kontemplacja szczegółu. To właśnie od konkretu rozpoczynają się uniwersalne opowieści Szubera o byciu w świecie. SŁOWA KLUCZOWE: Janusz Szuber; Polska poezja; Tłumaczenie na język portugalski; Inspiracje poetyckie.

Em setembro de 2019, o Fundo Editorial Polonês do Canadá, em parceria com a Sociedade Artístico-Literária "Fraza" publicou um opúsculo de poemas de um excelente poeta que goza de grande fama na Polônia, Janusz Szuber, natural de Sanok. Trata-se do tomo bilíngue, polonês-português, intitulado Próba dębu / Teste do carvalho (SZUBER, 2019). Composto por 25 poemas, selecionados e traduzidos por Zygmunt Wawrzyniec Wojski ${ }^{1}$, doutor em ciências humanas da Universidade de Wrocław, romanista, iberista, professor, tradutor de espanhol, português, romeno e polonês. A antologia de Szuber é dedicado aos leitores brasileiros, o que resta em alto e bom som confirmado na dedicatória: "Brazylijskim przyjaciołom - autor i thumacz. Aos amigos brasileiros - o autor e o tradutor" (SZUBER, 2019, p. 5). A obra, através de contatos pessoas dos editores e do tradutor, chegou a um círculo de pessoas interessadas em cultura polonesa fora da Polônia. O objetivo do meu artigo é aproximar a produção de Janusz Szuber, apontar suas fontes de inspiração e os temas mais importantes, tendo por base os poemas que chegam até nós nesta pequenina antologia. Para tanto, faço uso do método de análise e interpretação, pois ele permite liberdade investigativa, além da descoberta de variados sentidos e leituras de

\footnotetext{
${ }^{1}$ Deve-se salientar que este não é o primeiro encontro de Zygmunt Wawrzyniec Wojski com a poesia de Janusz Szuber. Já em 2012, ele foi responsável pela seleção e tradução de poemas seus para o espanhol. (SZUBER, 2012).
} 
alusões e écfrases. Considero que este posicionamento investigativo permitirá alcançar os mais interessantes traços da poesia do autor de Teste do carvalho.

A obra de Szuber, nascido em 10 de dezembro de 1947, em Sanok, é muito rica. O poeta, que debutou tardiamente, apenas em 1994 nas páginas do Tygodnik Sanocki, trouxe à estampa até agora 24 tomos de versos ${ }^{2}$. A poesia de Szuber foi traduzida para o alemão, o inglês, o francês, o espanhol, o búlgaro, o esloveno, o húngaro, o ucraniano, o croata, o sérvio, o neerlandês e o russo. Algumas traduções para português foram levadas a cabo em 2012 por Francisco José dos Santos Braga, que, nas páginas da revista Polonicus: Revista de reflexão Brasil-Polônia, publicou um artigo intitulado Homenagem ao poeta polonês Janusz Szuber (BRAGA, 2019, p. 149-162), no qual apresenta a biografia do poeta polonês e descreve a recepção de sua obra pelos críticos americanos. Próba dębu /Teste de carvalho permite a apresentação de uma seleção mais ampla de Szuber em língua portuguesa, a qual certamente não é casual, pois, como disse o poeta: "escolhendo qualquer coisa, escolho uma / das possíveis versões de mim mesmo" (SZUBER, 2019, p. 67$)^{3}$.

Dou início a esta viagem pelo mundo da poesia de Janusz Szuber a partir do poema Praça do mercado 14 apartamento 1 (Rynek 14/1), originalmente publicado no opúsculo com o mesmo título. Este é o endereço do apartamento do poeta em Sanok, o centro a partir do qual dirige sua observação poética:

O primeiro andar da casa junto da Praça do Mercado, a uns trinta metros de minha janela, estava ocupado desde 1916 por meu bisavô Maurício, durante seis dias da semana depois da sesta após o almoço descia ao térreo, ao gabinete com uma entrada separada desde a frente, ali onde agora há uma taberna e autômatos para os jogos, e antes, durante mais de meio século, havia um ateliê fotográfico para receber doentes entre as quatro e as seis horas e aliviar a natureza manchada pelo pecado [...]

(SZUBER, 2019, p. 59)

\footnotetext{
${ }^{2}$ Uma ampla bibliografia da criação de Janusz Szuber, entre 1994 e 2008, da pena de Alicja Bułdak pode ser encontrada em Pasterska; Rabizo-Birek (2008, p. 341-367); uma bibliografia de 2008 a 2019 está contida no trabalho de Jakubowska-Ożóg (2019, p. 191-233).
}

${ }^{3}$ No original: "Wybierając cokolwiek, wybieram jedną / z możliwych wersji samego siebie". 
Na antologia Teste do carvalho, este é o único poema em que Szuber dá a conhecer um fragmento da história de sua família. O bisavô do autor, mencionado no poema, é Maurycy Drewiński, um reconhecido e meritório ativista social e médico da cidade de Sanok. Szuber com frequência retorna a recordações líricas de sua família. Conforme escreve Alicja Jakubowska-Ożóg ${ }^{4}$ (2019, p. 43): "Em Szuber, a busca de suas impressões digitais é visível na procura pelas conexões familiares"5. O poeta descreve as escolhas de vida de seus antepassados, apresenta seus intrincados destinos, infortúnios, intrigas amorosas. Transfere aos poemas a intensidade de suas vidas, mostrando também como vieram a se tornar parte de sua identidade. Basta, aqui, fazer referência a um fragmento do conto de Natal de Szuber que desvela sua relação com o bisavô:

\begin{abstract}
À frente meu bisavô Maurycy, um forte homem mais velho, calvejando, e sua longa barba prateada; ele era primo, eu achava, de São Nicolau e de Francisco José I, tinha com eles uma plena identidade primeva. Então ele saía dos ramos verde-escuros com enfeites e deixava presentes sob a árvore de Natal; então eu the suplicava, desde o começo de dezembro, na esperança de que meus acalorados pedidos fossem ouvidos. Nosso laço secreto trouxe resultados a ele e a mim: eu recebia os presentes; ele, uma miúda imortalidade no mito privado da criança. Como se viu depois de muitos anos, este laço resistiu à prova do tempo e, agora, Maurycy aparece em meus versos (SZUBER; SZULC, 2005, p. 68).
\end{abstract}

A expressão de Szuber traduz literalmente o sentido da presentificação das figuras familiares. Referindo-se a elas nos poemas, termina por criar um excepcional e intrigante mito de sua própria família.

Ao refletir sobre a produção do poeta de Sanok, deve-se dar atenção ao fato de que, no fragmento trazido à lume, o bisavô Maurycy "desce" da imagem. O pequeno Szuber contempla o retrato do bisavô. Este é um elemento importante da imaginação poética do autor de Mojość, o qual se liga também ao seu funcionamento quotidiano. As paredes do apartamento de Szuber são ricamente enfeitadas com vários quadros, desenhos e fotografias. Sobressaem os desenhos de Leszek Rózga, mas também há trabalhos de

\footnotetext{
${ }^{4}$ Salvo indicação em contrário, as versões em português das citações ao longo do artigo são traduções de Luiz Henrique Budant.

${ }^{5}$ No original: "Szukanie swych linii papilarnych jest u Szubera widoczne w śledzeniu rodzinnych koneksji”.
} 
Henryk Waniek, Władysław Szulc, além de quadros de Nikifor Krynicki ${ }^{6}$. Diz o poeta sobre sua galeria caseira, particular:

Surgiu algo a que chamo de "pequena iconóstase". Passo a maior parte do ano em casa, então a adaptação das paredes, por entre as quais eu me movimento, é um assunto fundamental. É difícil refletir todo o dia sobre quando se vai tomar os remédios ou o que vai ter para o almoço. Sempre encontro um momento para curtas sessões de contemplação diante de um ou dois quadros de minha coleção (SZUBER, 2016). ${ }^{7}$

Essa contemplação é frequentemente trazida por Szuber a seus trabalhos, o que é fácil de se perceber também na antologia em língua portuguesa. Encontraremos o interesse pelo espaço da pintura no poema intitulado Quem desce da nuvem (Zstepujacy z chmury, SZUBER, 2019, p. 11). O poeta conta aqui, com precisão, a fonte de sua observação poética. Trata-se do ícone de João Batista, originário de uma das mais antigas igrejas greco-católicas da Polônia, em Ulucz, um vilarejo distante pouco mais de 20 quilômetros de Sanok. O aproveitamento do motivo não é ocasional, pois ele é característico da paisagem cultural da Subcarpácia ${ }^{8}$. O ícone de João Batista é parte da iconóstase que se encontra no Museu de Arquitetura Popular de Sanok. Pode-se encontrar uma fotografia

${ }^{6}$ A obra primitivista de Epifaniusz Drowniak (conhecido como Nikifor Krynicki), pintor polonês
de origem łemko é muito importante para Szuber. No poema intitulado Quem, o qual contém
elementos da biografia do poeta (menções à doença por conta da qual precisa usar cadeira de
rodas) encontramos intrigante fragmento que fala sobre "o encantamento por Nikifor Milagreiro"
(SZUBER, 2019, p. 39). Magdalena Rabizo-Birek, explicando as dimensões deste "encantamento",
chama atenção que "mais fundamental parece [...] a dimensão íntima da vocação poética, na qual
o presente da criação é pago (ou marcado) pela doença [...]" (RABIZO-BIREK, 2008, p. 216).
No original: "Najbardziej istotny wydaje się [...] intymny wymiar artystycznego powołania , w
którym dar tworzenia jest okupiony (lub naznaczony) chorobą [...]" (RABIZO-BIREK, 2008, p.
216).

${ }^{7}$ No original: “Powstało coś, co ja nazywam ,ikonostasem małym”. Większą część roku spędzam w domu, więc zagospodarowanie ścian, wśród których się poruszam, jest sprawą istotną. Trudno się cały dzień zastanawiać nad tym, kiedy przyjmuje się leki albo co będzie na obiad. Zawsze znajduję chwilę na krótkie sesje kontemplacyjne nad jednym czy nad dwoma obrazami z mojej kolekcji”.

${ }^{8}$ Veja-se: <https://zabytek.pl/pl/kolekcje/koscioly-i-cerkwie-na-szlaku-architektury-drewnianejwojewod> Acesso em: 15 out 2019. Convém aqui mencionar que algumas das igrejas se encontram na lista do Patrimônio Mundial da UNESCO, entre elas as de Chotyniec, Radruż, Smolnik e Turzańsk. 
da mencionada iconóstase no sítio eletrônico de Ulucz ${ }^{9}$. Procedendo à análise do ícone e comparando-o com a observação contida no poema de Szuber, é possível facilmente se convencer de que se trata de uma descrição fiel da figura de João Batista que se encontra no centro:

Estou diante dele - este Anjo do Deserto:

Pernilongo, com grandes asas, temeroso.

Em volta do rosto, uma oval de barbas escuras,

Uma boca miúda, pálpebras grossas, bojudas.

Com a mão esquerda segura o rolo da Escritura,

Desenvolvido, que com letras cirílicas desce das nuvens,

O braço direito dobrado no cotovelo, levantado

Segundo mandam os cânones respeitosos.

Junto da enorme e nua barriga da perna

Crescem umas árvores chegando aos joelhos.

(SZUBER, 2019, p. 11)

Na parte final do poema, a atenção do eu lírico fixa-se em um detalhe que se torna pretexto para uma reflexão relacionada à experiência estética. A observação do detalhe e a contemplação do objeto são, afinal, um traço muito importante e característico da produção artística de Szuber:

No ramo está pendurado o machado

De um lenhador ou um carpinteiro dos Cárpatos

Para eu ver a verdade tangível das palavras

Sobre o machado posto já no tronco.

(SZUBER, 2019, p. 11)

O eu lírico, contemplando a imagem, transpõe os elementos de segundo plano do cenário para a Subcarpácia. Lenhadores e carpinteiros são profissões que se relacionam à vida quotidiana dos moradores da região de Bieszczady, da cadeia de montanhas dos Cárpatos. Portanto, a observação da imagem reduz-se ao espaço familiar e, ao final, fecha-se na experiência individual do eu lírico, que interpreta a simbologia do machado pendurado na árvore através do contexto bíblico, extraído do Evangelho de Mateus. O fragmento faz referência à pregação de João Batista que, anunciando a vinda do Cristo, exorta todos à conversão, nos seguintes termos: “o machado já está posto sobre a raiz das árvores; toda árvore, que não der bons frutos, será cortada e lançada ao fogo"(BÍBLIA SAGRADA, 2005- Mt. 3,10). Szuber nos oferece uma interessante possibilidade de

${ }^{9}$ Cf. $<$ http://www.ulucz.org/?p=2372> Acesso em: 15 out 2019. 
interpretação dos sentidos outros do ícone, apresenta o momento do encontro com a obra do pintor $^{10}$, na qual aparecem os sentidos adicionais, que oferecem uma sugestão acerca da qualidade da vida, marcada pelo contexto da experiência religiosa.

Permanecendo, ainda, no nível pictórico do opúsculo de Szuber, não se pode olvidar de um importante contexto estético: a capa, na qual se encontra uma reprodução da obra de Zdzisław Beksiński (1986), eminente artista, pintor, escultor, fotógrafo e desenhista que morava em Sanok. Na obra sobre a qual nos debruçamos, Szuber dedica a Beksiński um breve poema, em que mostra a excepcionalidade do encontro com a criação do artista, descrevendo a experiência interna do ser humano que as admira: De quem os olhos em minha cara, De quem os pensamentos girando Como um bando de pássaros.
De quem a pele que me envolve, De quem o calor interior E a árvore de respiro enraizada Cá dentro de meu pulmão? (SZUBER, 2019, p. 29)

De quem será o coração que bate em meu peito,

O receptor para, pois, diante dos segredos das imagens, os quais despertam uma forte experiência que transpassa os sentidos e confundindo os pensamentos. Trata-se de acurada observação poética das fantásticas e inquietantes obras de Beksiński, as quais pode-se ver no Museu Histórico de Sanok.

Voltemos, contudo, à capa do opúsculo. A reprodução apresenta árvores fantásticas e misteriosas, com o verde intenso iluminado da copa, troncos escuros e galhos cujas bases se entrelaçam em inquietantes tons de violeta, rosa e cereja. A clara correspondência entre o tema da pintura de Beksiński e o poema de Szuber intitulado Teste do carvalho permite, por um lado, apontar de modo inequívoco a origem comum das obras, enfatizar o local de criação, o surgimento de um mundo em comum, mas, por outro lado, permite enxergar como a arte e a poesia podem, com soberba, se definir e se completar, pois, ao olharmos

\footnotetext{
${ }^{10}$ No tomo Próba Dębu/Teste do carvalho, encontra-se o poema Oto/Eis aqui (SZUBER, 2019, p. 20-21), no qual é descrito o quadro Anunciação da Santíssima Virgem Maria, que se encontra na igreja da Assunção da Santíssima Virgem Maria, em Zagórz. Em comentários ao poema, informase que, ao lado da tradição da igreja oriental e dos ícones a ela relacionados, desenvolveu-se, também na região de Bieszczady, um culto mariano. Através do uso da écfrase, Szuber mostra a identidade religiosa dessa região, o que também é um traço importante de sua obra.
} 
as excepcionais árvores de Beksiński, não nos ficaria mais fácil compreender o herói do poema, quando diz:

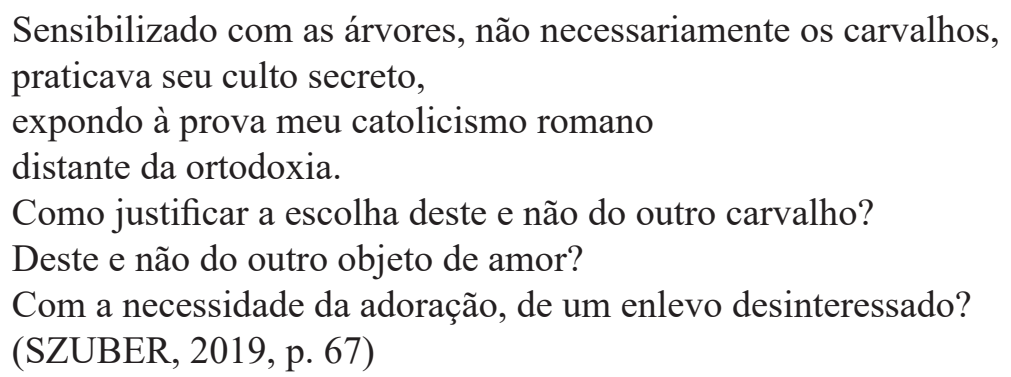

O aparecimento do carvalho faz, certamente, referência à obra de Zbigniew Herbert, um dos maiores poetas poloneses, que efetivamente encorajou Szuber no início de sua carreira poética e atuou para a divulgação de sua produção (FRANASZEK, 2018, p. 777-778). No início da obra Elegia para a partida, Herbert inseriu o poema Carvalhos, o qual se inicia, como no homólogo de Szuber, pela observação das árvores:

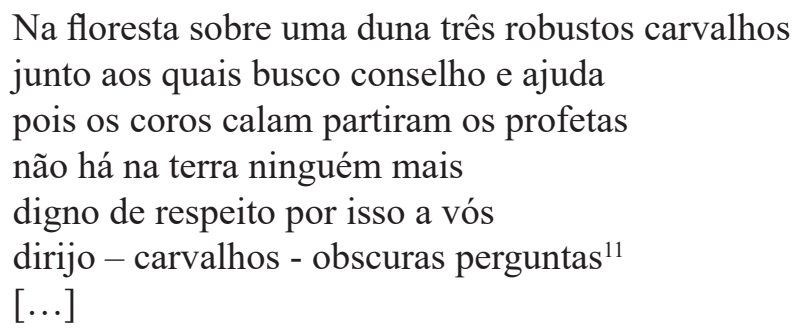

Pergunta-se o sentido da existência, as causas do sofrimento, da solidão, da crueldade. Contudo, as respostas não chegam. A natureza se cala, deixa de ser remédio para o desespero causado pela consciência da inevitabilidade do mal do mundo. Esta visão pessimista e penetrante do mundo não aparece no poema de Szuber. O carvalho torna-se, para ele, um símbolo da natureza primeva, um ponto de orientação seguro e importante nos caminhos da vida.

No caso do poema Teste do carvalho, convém ainda levar em conta um contexto, qual seja, a poesia de Friedrich Hölderlin, poeta alemão e precursor do romantismo, cuja lenda tornou-se inspiração para muitos poetas. Szuber faz referência à biografia do poeta no poema intitulado simplesmente Hölderlin. Na segunda estrofe, que se assemelha a uma espécie de monólogo interior de Hölderlin, lemos:

${ }^{11}$ HERBERT, Zbigniew. Carvalhos (trad. Piotr Kilanowski) in: KILANOWSKI, 2018, p. 774. 
Já somente comigo na torre grisalha Alojou-se Kyrios Dionizos. O pastor Bondoso do continente antanho tão fértil. Sim, sim - repito. Esta torre tem ouvidos. (SZUBER, 2019, p. 61)

A torre que aparece nestes versos é, evidentemente, o famoso local na cidade universitária de Tubinga (Tübingen, em alemão), no sudeste da Alemanha, onde Hölderlin, padecendo de transtornos mentais, passou quase 36 anos de sua vida. Este lugar é um axis mundi particular da biografia do poeta. A menção a Dionísio leva a um ponto simbólico na vida de Hölderlin, sua viagem hibernal, a pé, para Bordeaux e o retorno pelas montanhas, em que "viria a lhe aparecer Apolo, ou Dionísio, com quem travou um 'discurso fundamental' que definitivamente o 'paralisou'" (LIBERA, 2009, p. 7). Esta cisão entre a paranoia e o gênio poético se tornou uma das fontes do fascínio por Hölderlin. O poeta alemão é conhecido pelo uso de temas da natureza e sua relação com o homem. Eis que, aqui, voltamos ao Teste do carvalho, pois precisamente neste poema Szuber tenta mostrar uma relação semelhante. O poeta admira um carvalho localizado na curva da estrada, recordando a dificuldade de explicar o fascínio pela árvore. Parece evidente o parentesco do poema de Szuber com aquele de Hölderlin, intitulado nomem omen Os Carvalhos (Die Eichbäume). Nele, o poeta alemão dirige-se aos carvalhos na apóstrofe:

\footnotetext{
Saindo dos jardins, vou até vós, oh! filhos da montanha; dos jardins onde, paciente e caseira, a Natureza convive Com os homens diligentes, cuidando e sendo deles cuidada. Mas vós vos ergueis, altivo povo de Titãs, em meio A mundo mais dócil, só de vós mesmos dependentes, E do céu que vos nutriu e educou, e da terra que gerou-vos. (HÖLDERLIN, 1991, p. 61)
}

Hölderlin termina o poema com a afirmação de que, não fosse o amor à vida entre os homens, poderia viver entre os carvalhos. Semelhante solução observamos no poema de Szuber. O eu lírico viaja em seu carro e cumprimenta a árvore levantando a mão e buzinando três vezes. Está em uma viagem contínua. Vai e volta. Fascina-se pelo carvalho, observa-o no outono e na primavera. Percebe sua permanência diante da passagem das estações do ano. Dá acento à transitoriedade, mas também à repetibilidade que compõe a corrente da vida, a estabilidade da natureza, sua primordialidade, sua majestade, diante da qual às vezes paramos e pensamos sobre a própria existência. 
Szuber com excelência consegue capturar precisamente estes momentos. Como no poema Nevoeiro (Mgła), no qual, viajando ao longo do rio San, observando a paisagem autunal das cercanias de Sanok, de súbito adentra-se no nevoeiro: "E de repente / Engoliu-nos o nada leitoso, cada vez mais espesso, / E apenas víamos as pupilas das luzes anti-nevoeiro / Junto do asfalto" (SZUBER, 2019, p. 15). E este encontro com o nevoeiro torna necessário confrontar-se consigo mesmo: "contar estórias de mim para mim" (SZUBER, 2019, p. 15), dirá o poeta. No Pequeno tratado sobre as analogias (Mały traktat o analogiach), (SZUBER, 2019, p. 17) descreve, com efeito, uma situação em que o eu lírico dentro do carro, esperando por uma mulher, examina uma abelha, a qual tenta em vão voar para fora do veículo. Essa situação é transformada pelo poeta em uma metafórica "parábola sobre a existência", da qual extrai uma convicção algo incerta de que os atos bons contra os menores seres que habitam este mundo retornarão no futuro.

Peguei na agenda onde estou

Anotando este acontecimento, e com ajuda dela

Encaminhei a abelha para a porta entreaberta, Crendo, embora não totalmente, que um dia Alguém faria o mesmo comigo.

(SZUBER, 2019, p. 17)

Szuber, nos versos finais, apresenta uma curiosa solução que permite de uma dupla maneira determinar a possibilidade de receber paga por oferecer ajuda ao inseto benéfico. Ele apresenta as expressões coloquiais "um dia... alguém..." que se podem referir a uma ajuda futura por parte de outro ser humano, mas também faz uso da tradição poética de usar letras maiúsculas no início do verso, o que muda o sentido, pois a palavra "alguém" pode referir-se diretamente ao Criador. Trata-se, é evidente, de uma perspectiva interpretativa mais ampla. Szuber aponta, portanto, como nos irrepetíveis instantes de nossa vida surgem momentos nos quais nos voltamos em direção ao mistério do fim da existência ${ }^{12}$.

Seguir pela rota dos poemas que se encontram nesta antologia traduzida para a língua portuguesa do Brasil permite conhecer parte da problemática e dos temas de que se ocupava Janusz Szuber. São eles: uma mitologia familiar, o espaço de Sanok e da região de Bieszczady, o fascínio pelos ícones, pela pintura de Nikifor Krynicki e Zdzisław

${ }^{12}$ O tema também é tocado por Szuber no poema Oitava (2019, p. 23). Uma interessante análise deste poema foi apresentada por Sulikowski (2018, p. 42-45). 
Beksiński, o diálogo poético com Friedrich Hölderlin, Juliusz Słowacki ${ }^{13}$, Zbigniew Herbert, a contemplação do detalhe, a observação da natureza, a memória e a nostalgia. Trata-se, é claro, de uma pequenina tentativa que dá a conhecer uma parte da fase do poeta, mas permite, sobretudo, que seus espaços poéticos ganhem existência em lugares distantes de sua terra natal. Esta existência é possível graças ao universalismo que o relato de Szuber sobre o estar no mundo torne-se vivo e intenso.

Tradução: Luiz Henrique Budant

${ }^{13}$ Como o poema Niczego więcej/ Mais Nada (SZUBER, 2019, p.44-47). 


\section{REFERÊNCIAS:}

BEKSINSKI, Zdzisław. EV. 1986. Pintura, óleo em painel de madeira, 132 x 98,5 cm.

BÍBLIA SAGRADA. Petrópolis, RJ: Vozes, 2005.

BRAGA, Francisco José dos Santos. Homenagem ao poeta polonês Janusz Szuber. Polonicus. Revista de reflexão Brasil-Polônia. Curitiba, 2012, n. 1, p. 149-162. Disponível em: $\quad<$ https://www.polonicus.com.br/arquivos/pdf-pl-2012-08-20\%2015-23-29.pdf>. Acesso em 17 out 2019.

FRANASZEK, Andrzej. Herbert. Biografia. t.2. Kraków: Wydawnictwo Znak, 2018.

HÖLDERLIN, Friedrich. Poemas. Trad. José Paulo Paes. São Paulo: Companhia das Letras, 1991.

JAKUBOWSKA-OŻÓG, Alicja. Wcałowzięty. Szkice o poezji Janusza Szubera. Rzeszów: Wydawnictwo Uniwersytetu Rzeszowskiego, 2019.

KILANOWSKI, Piotr. „Queria permanecer fiel à clareza incerta...”: Sobre poesia de Zbigniew Herbert. 876 p. Tese (doutorado) - Universidade Federal de Santa Catarina, Centro de Comunicação e Expressão, Programa de Pós-Graduação em Literatura, Florianópolis, 2018. p.774.

LIBERA, Antoni. Noc dziejów nadal trwa. In: HÖLDERLIN, F. Co się ostaje, ustanawiaja poeci. Trad. de Antoni Libera. Gdańsk: Wydawnictwo Słowo/obraz terytoria, 2009. p. $5-25$.

PASTERSKA, Jolanta; RABIZO-BIREK, Magdalena (Orgs.). Poeta czułej pamięci. Studia i szkice o twórczości Janusza Szubera. Rzeszów: Wydawnictwo Stowarzyszenie Literacko-Artystyczne "Fraza", 2008.

RABIZO-BIREK, Magdalena. Zaczarowany przez Nikifora cudotwórcę. Motywy plastyczne poezji Janusza Szubera. In: PASTERSKA, J.; RABIZO-BIREK, M. (Orgs.). Poeta czułej pamięci. Studia i szkice o twórczości Janusza Szubera. Rzeszów: Wydawnictwo, 2008. p. 211-230.

SULIKOWSKI, Andrzej. Rynek i coraz dalsze okolice. O twórczości Janusza Szubera. Kraków: Polskie Wydawnictwo Muzyczne, 2018.

SZUBER, Janusz. Entelechia / Entelequia. Trad. de Z. Wojski. Rzeszów: Biblioteka "Frazy", 2012. 
SZUBER, Janusz. Kormorany same do mnie przyleciały. Tygodnik Powszechny, 22 dez 2016. Entrevista concedida a Katarzyna Kubisiowska, Disponível em: $<$ https://www.tygodnikpowszechny.pl/kormorany-same-do-mnie-przylecialy146179? language $=\mathrm{pl} \% 22 \% 20 \backslash \mathrm{h}>$. Acesso em 17 out 2019 .

SZUBER, Janusz. Próba dębu / Teste do carvalho. Trad. De Z. W. Wojski. Toronto, Rzeszów: Polski Fundusz Wydawniczy w Kanadzie, Biblioteka "Frazy”, 2019.

SZUBER, Janusz; SZULC, Władysław. Mojość. Sanok: Oficyna Wydawnicza Miejskiej Biblioteki Publicznej im. Grzegorza z Sanoka, 2005. 